\title{
Competitive Benchmarking Adoption Issues in the Hotel Sector in Petra, Jordan
}

\author{
Naseem M. Twaissi ${ }^{1} \&$ Jebril A. Alhelalat ${ }^{2}$ \\ ${ }^{1}$ Department of Business Administration, Faculty of Business Administration and Economics, Al-Hussein Bin \\ Talal University, Jordan \\ ${ }^{2}$ Department of Hotel and Tourism Services Management, Petra College for Tourism and Archaeology, \\ Al-Hussein Bin Talal University, Jordan \\ Correspondence: Naseem M. Twaissi, Department of Business Administration, Faculty of Business \\ Administration and Economics, Al-Hussein Bin Talal University, Jordan. E-mail: naseem_petra@hotmail.com
}

Received: March 15, 2015 Accepted: April 15, 2015 Online Published: May 31, 2015

doi:10.5539/ijms.v7n3p53 URL: http://dx.doi.org/10.5539/ijms.v7n3p53

\begin{abstract}
The study's aim was to understand the level of benchmarking adoption, its objectives and limitation among the hotel sector in Petra, Jordan. Through twelve semi-structured interviews with the hotel owners and managers, the study concluded that the hotel sector in Petra adopts the benchmarking concepts moderately. The study also revealed that competitiveness is the most important reason behind the adoption of benchmarking. Hotels benefit from benchmarking in market trends and being competitive. One important result is that the regional political conditions in the Middle East and the consequences of the Arab spring are the most important obstacles that prevent the adoption of benchmarking in the hotel sector in Petra. To the authors' best knowledge, this study unprecedentedly integrates benchmarking using qualitative methods in researching the hotel sector in Petra.
\end{abstract}

Keywords: quality management, benchmarking, tourism, hotel sector, Arab spring, Petra

\section{Introduction}

Hotels operate in a highly competitive market and therefore place a strong emphasis on quality management in order to gain and maintain competitiveness (Patiar, Davidson \& Wang, 2012). Applying the principles of service quality and Total Quality Management (Henceforth; TQM) is of great interest for both academics and practitioners in the tourism and hotel sector as well as in the other sectors. Accordingly, Abukhalifeh \& Som (2014) suggested, based on a literature review, that quality problems can be solved through placing customer needs in the heart of the whole process of quality vision, initiation, planning, delivery, monitoring and sustainability; seeking suggestions from staff; developing corporate quality and people philosophy; training and empowering staff; benchmarking and reviewing. Furthermore, studies on quality have thoroughly tackled benchmarking. Benchmarking is a systematic procedure for comparative measurements with the aim of realizing continuous improvement (Kosar, 2011). Narayan, Rajendran \& Sai (2008) adopted a definition of benchmarking that calls for a process of measuring an organization's own performance against the of best-in-class organizations. They stressed on the fact that benchmarking is different in services from manufacturing organizations; the variation of quality concepts and applications is the main reason.

Tourism, a highly competitive industry, is considered an important sector and a main source of foreign exchange earnings in many countries. It is furthermore the sine qua non to Arab countries' economy, including Jordan, for balance-of-trade purposes and the development of infrastructure (Mustafa, 2010). However, the tourism sector in Arab countries witnessed a significant decline after the Arab Spring Revolutions, as a result of the insecurity and political conditions in countries such as Tunisia, Egypt, Yemen, Syria and Libya, and an indirect effect in Morocco, Jordan and Lebanon. The impact of such events has led to a significant decline in this sector (Ali, Arifin \& Hasim, 2012; Al-Hamarneh, 2013). Although benchmarking has become established in the culture of both the manufacturing and service industries, studies that deal with tourism businesses are meagre (Kozak, 2002). Therefore, it is of great significance to assess the adoption of benchmarking within the tourism and hotel sector in Jordan in order to identify its competitive position in comparison with other countries. 
Jordan, which is a popular tourist destination in the Middle East, is known for the Dead Sea (the lowest point on earth), the Baptism site and Petra. Petra is one of the new Seven Wonders of the World, one of the world heritage sites and the major tourism attraction in Jordan. Taji (2004) described Petra as an iconic tourist destination in Jordan. Moreover, the competitiveness of the tourism market in the Middle East is relatively high, especially with countries well-known internationally for their heritage, rich history and business potential, such as Egypt, Dubai and Morocco (Hazbun, 2006). Because Jordan is highly influenced by the political atmosphere in the region, the tourism income and the number of visitors fluctuate as a response to the conflicts in the region. Nevertheless, tourism comprises an average of $10-13 \%$ contribution to the GDP, with more than 48,000 jobs. The number of hotels in Petra (at the end of 2014) was 40 hotels that have 2,182 rooms and 1,164 workers (Ministry of Tourism and Antiquities, 2014).

Based on the above discussion, the population of the research, which is Petra hotels, is worth studying in the context of the current study because of their high potential and relative economic importance. It is thought that there is a lack of studies that examine the tourist services in Petra, especially benchmarking and competitiveness issues; most previous research efforts have focused on the aspect of the archaeological Petra. Meanwhile, there are few studies that discussed benchmarking and competitiveness in Jordan. Hayek, Haddad, Mosa, Al-Atiyat, Buser, Mutz \& Zein (2008) researched the side of environmental benchmarking within the hotel sector in Jordan. Attiany (2014) studied benchmarking in the Jordanian stock market. Al-Fawaeer, Hamdan \& Al-Zu'bi (2012) and Al-Tarawneh (2014) investigated benchmarking in the Jordanian banking sector. However, competitive benchmarking lacks research in the hotel sector.

Accordingly, three areas are to be studied; namely the degree of adoption of benchmarking, the objectives of benchmarking, and limitation and obstacles of benchmarking employment within the sampled hotels.

\section{Literature Review}

Benchmarking as a quality tool is widely researched in the TQM literature (Tavana, Mohebbi, \& Kennedy, 2003; Sajjad \& Amjad, 2012), while competitive benchmarking is the focus of this study as a performance measure not only in quality, but in performance related to competition. Competitive benchmarking is mainly related to indicators such as relative market share and position, sales growth, and measures of customer base (Zigan \& Zeglat, 2010). In addition, Kosar (2011) mentioned price, product, level of service, location, and distribution channels as criteria for competitive benchmarking.

In view of that, there is a trend that quality issues are of great importance to win customers and compete better (Patiar et al., 2012), it is apparent in the literature that TQM can be applied in any organization in any sector, including, manufacturing, services and government (Jaafreh \& Al-abedallat, 2013). Employing TQM principles and practices can create more satisfied customers, reduce costs, enhance competitiveness and increase productivity. In the competitive environment, organizations whose quality of services have stronger competitive position to attract customers to buy, repeat buying their products and services than those that have poor quality. When it comes to improving quality and competitive position, quality indicators are of great importance to service organizations, including hotels (Patiar et al., 2012). Hence, organisations must embrace strong acceptance and maintenance of total quality measurement and benchmarking plans according to Motwani (2001). The benefits of these quality measurements techniques are summarized as controlling process to verify variations; determining problem areas, opportunities, savings and action priorities; pinpointing potential improvements; and controlling quality management and performance (Ahire, Golhar \& Waller, 1996; Roden \& Dale, 2000; Oakland, 2003; Biazzo \& Bernardi, 2003; Al-Omaim, 2003; Ford, Evans \& Matthews, 2004; Evans, 2005).

As mentioned earlier, benchmarking is considered a way of comparing products and services with those operate in relevant industry; it is directly linked with quality assurance, and quality improvement (Inglis, 2005). By definition, Freytag \& Hollensen (2001) viewed benchmarking as a way of measuring an organisation's strategies and performance against best-in-class organisations, both inside and outside their own industry. The purpose is to identify the best practices that can be adopted and implemented by the organisation with the purpose of improving organization's performance and competitiveness.

Benchmarking is used in businesses to assist in understanding the technical and financial implications of environmental retrofits and employee training (Abukhalifeh \& Som, 2014). Goldstein \& Primlani (2012) viewed benchmarking as the way that provides a means to evaluate organization's performance against similar organizations to preliminarily ascertain the potential for operational performance improvements.

Ravikanth \& Reddy (2014) reported Zairi \& Leonard's (1994) benchmarking methods such as Competitive benchmarking (an examination with an immediate competitor); Internal benchmarking (best practices internally); Functional benchmarking (the specific functions with similar functions that are best in class); and Generic 
benchmarking (processes that extend across functional barriers and organization sectors). In addition, they also reported the steps of conducting benchmarking as:

1) Planning: identify what is to be benchmarked, identify comparative companies, determine data collection method and collect data.

2) Analysis: determine current performance gap, project future performance levels.

3) Integration: communicate benchmark findings and gain acceptance, establish functional goals.

4) Action: develop action plans, implement specific action and monitor progress, recalibrate benchmarks.

5) Maturity: leadership position attained, best practices fully integrated into process.

Kosar (2011) considering the hotel sector has mainly viewed benchmarking as assessing the competitive position of a hotel by comparing its services with target hotels in relation to business strategy and quality indicators. This approach needs a specific focus on monitoring the basic indicators of business in relation to performance and efficiency. In addition Milohnić \& Cerović (2007) stressed that the implementation of quality in the hotel sector requires the continuity of following market trends and the need for constant comparison with the best competitors in the tourist market, which involves benchmarking specific performance indicators with the best practice within competition globally. Benchmarking is part of business improvement processes and not a one-time project; Bergin, Jago \& Deery (2000) stated that the benefits of benchmarking in tourism include the identification of customers' needs, being cost-effective, identifying organization's strengths and weaknesses, and encouraging continuous improvement as a quality measure. Ravikanth \& Reddy (2014) stated that the awareness of benchmarking in tourism develops the ability of planning for better quality improvement.

Furthermore, there was a strong emphasis on importance of the changing environment and external factors in the change of organizations competitiveness in tourism; however, efficiency improvement, effective marking, training, and benchmarking were suggested ways to survive in the changeable tourism business environment (Eraqi, 2006). Benchmarking is used in this context to ensure quality improvement through the continuity of following the market trends which leads organizations towards better results of performance (Eraqi, 2006; Milohnić \& Cerović, 2007). Patiar et al. (2012) concluded that TQM and market competition affects hotel departmental performance and leads to overall performance improvement. TQM is deployed by organizations for its ability to enable better performance in relation to financial performance; operational performance; product quality; customer service and satisfaction; and employee relations. In addition, Eraqi (2006) concluded that in order to improve the quality of service in tourism, there is a need for internal employee satisfaction, external customer satisfaction and efficient processes within the organization.

Organizations employ benchmarking for different reasons. It can increase productivity, or an individual design. By simply looking outside itself, an organization can identify breakthroughs in thinking. A similar process used in a different way can shed light on new opportunities to use the original process (Asrofah, Zailani \& Fernando, 2010). Freytag \& Hollensen (2001) pointed out that the main aim of benchmarking is to improve products and processes in order to meet customer requirements better. The benchmarking step was perceived to make benchmarking effective and resulted in increasing profitability, maintaining and increasing the competitive advantage (Kumar \& Chandra, 2001). Benchmarking also gives companies a chance to learn new and innovative approaches to issues facing management which, in turn, provides the basis for training. Benchmarking is considered a tool to improve performance by assisting in setting achievable goals that have already been proven successful (Elmuti \& Kathawala, 1997).

Within the context of the need for benchmarking, Ross (1999) suggested three justifications for organisations to embark on benchmarking activities. They are culture change, performance improvement and human resources. As far as culture change is concerned, benchmarking allows organisations to set realistic, rigorous new performance targets. With respect to performance improvement, benchmarking allows the organisations to define specific gaps in performance and to select the processes to improve. As regard human resources, benchmarking provides a basis for training.

In addition, organizational performance can be assessed through customer retention, reliability, personalization of services, and creating value for money in the customers' view (Jaafreh \& Al-abedallat, 2013). The factors of quality of product, employees, quality of service, customer satisfaction, location and the quality of the infrastructure can be measured and benchmarked against the competitors in order to provide a sustainable competitive advantage (Melia, 2011).

In another view, measuring performance is a process achieved through the indictors of customer loyalty (meet and exceed customer expectations, accurate delivery of services, helpful and knowledgeable staff, and caring and 
individual attention to customer), attracting new customers (through business partnerships, knowing customers, appropriate marketing media), and innovation services and organizational environment. This requires an innovative combination of benchmarking techniques through cross-organizational development (Cano, Drummond, Miller \& Barclay, 2001).

Eraqi (2006) suggested that quality in tourism as a sector needs a special attention in relation to infrastructure, safety and security issues, people awareness and specific service quality concerns. This view is concerned with Egyptian tourism sector according to Eraqi (2006); however, there is a need for generalizing this note throughout the tourism industry globally. Milohnić \& Cerović (2007) suggested price, interior and specific market trends as indicators to be used in benchmarking comparison. Kapiki, Mou \& Fu (2014) focused on the importance of benchmarking in hotels concerning profitability and efficiency. Suttapong \& Tian (2012) stressed that benchmarking is highly regarded as a good technique to encourage and enables business improvement. Moreover, performances benchmarking also assists organization to understand their weaknesses and strengths, business and operational objectives against those of competitors.

Although benchmarking is widely used in different types of businesses, not all organisations find it easy to benchmarking tools lose effectiveness as a result of lack of a complete understanding of it (Kumar \& Chandra, 2001). Some problems with benchmarking may occur due to an organization's failure to implement the process properly. For example, a potential pitfall of benchmarking is the lack of actively involving employees during the process. These employees will be the ones ultimately using the information and improving the process (Omachonu \& Ross, 1994).

In more specific country-based context, Eraqi (2006) stated that one of the main obstacles of using innovative and latest quality improvement techniques in Egypt was the family business management. Bergin et al. (2000) mentioned business size, poor planning and evaluation, cost issues, staff knowledge and skills, lack of accurate data of competitors' performance as important barriers to benchmarking in tourism. Within the same context, Al-ababneh (2014) concluded that large hotels (international four and five star hotel chains) are more likely to adopt TQM techniques, including continuous improvement and benchmarking, in a way that is better than those independent smaller size hotels, which backs up the fact that the size of organization is an important obstacle in adopting latest benchmarking techniques.

Some companies have difficulty in treating benchmarking as continuous process. It should not be viewed as a one-time project. Additionally, some companies feel that if the tactic is not invented by them, it may be inferior. In addition, some companies avoid looking to benchmark because it reflects their weaknesses. Another common problem with benchmarking is the failure to expand the scope of companies studied. Potential companies to benchmark should include companies in all industries, even those outside of the user company's industry (Omachonu \& Ross, 1994).

Accordingly, the level of benchmarking adoption, benchmarking objectives and limitations are the major general topics that can assess the understanding of the concept and its application within the hotel industry in Petra. Therefore, they are the focus of the study.

\section{Methods}

Data collection used semi-structured interviews with the hotel owners and managers. The sample was taken from interviewees chosen from twelve hotels using self-selection sampling. The managers were interviewed individually and each interview took about thirty to forty minutes. The questions included both open-ended and some close-ended questions within the pre-determined three aspects of the research: the level of adoption of benchmarking; the objectives of benchmarking; and limitations and obstacles preventing the proper benchmarking techniques.

It was stated in the research methods references that there is no standardised approach to the analysis of qualitative data; however, there are many qualitative research traditions and approaches resulting in different strategies that deal with the collected data (Saunders, Lewis \& Thornhill, 2003). While different approaches can be combined, there is an emphasis on thematic analysis approach as the most appropriate for using in such research. Thematic analysis focuses on the content of the speech; hence, the content is considered rather than the form (Riessman, 2004).

The qualitative data collected through the interviews was processed and analysed starting with listening carefully to the tapes, transcribing each participant's response on a separate paper. Processing and analysing interviews normally takes time due to the need for careful transcription, and repeatedly reading and re-reading (Drever, 1995). Therefore, accurate reading was performed in order to identify the topic area related to the objective of 
the study. Then, all responses to the same question were put together and re-written on the same paper so that all the answers to a particular question could be classified together. Categories related to the research objectives were developed and relevant data was placed under each category. Then, the transcribed data was described in terms of the topics or categories and quotes were used for illustration.

\section{Results and Discussion}

\subsection{The Adoption Level of Benchmarking}

With respect to the first question about the adoption of quality benchmarking in the hotel sector in the city of Petra, the majority of respondents indicated that their businesses applied benchmarking of which they are aware, but each participant applied benchmarking differently. Two of the participants in the interview had good knowledge and used benchmarking concepts which reflect an awareness of these concepts. One of the participants said:

We are always working to monitor the most successful institutions in the world. We are trying to figure out what is the secret of success of this company and what is the best application that led to this success, and through information that was collected and analyzed. Then we compare that to our reality and take advantage of the results of this analysis and see if we can adopt some of their methods to improve our decision making.

Six participants had average knowledge and adoption of benchmarking. Some showed good knowledge but the application process was not clear, while others spoke about the application without showing that they had a clear awareness. Four of the participants talked about the importance of successful models and made a reference to them but did not have a systematic collection of information about the model. Some wanted internal competition between departments.

The remaining four participants had little knowledge and limited adoption of benchmarking, even though they are seeking to be competitive. Three showed a strong desire to learn and apply benchmarking concepts.

Table 1. The level of benchmarking adoption

\begin{tabular}{lll}
\hline The adoption level & Number of participants & Percentage \\
\hline High & 2 & 16.67 \\
Medium & 6 & 50 \\
Low & 4 & 33.33 \\
\hline
\end{tabular}

The results of the first question revealed that the participants who have medium levels of knowledge and adoption of benchmarking concepts were the highest. The investment community in services in Petra is relatively new and do not have a lot of experience in these concepts. Moreover, the researchers' experience indicates that there are large number of family businesses in the hotel sector in Petra, which supports the literature conclusions that small size and family-owned businesses have less adoption of quality measurements and benchmarking according to Eraqi (2006) and Al-ababneh (2014).

\subsection{The Objectives of the Application of Benchmarking in the Hotel Sector}

Participants talked about the objectives of adopting benchmarking, the vast majority focused on increasing competitiveness. While seven out of twelve participants mentioned that the main reason behind applying benchmarking is to improve the quality of outputs and to achieve customer satisfaction. Six stated that benchmarking is applied to improve performance, to increase profitability, and to achieve effectiveness. Five mentioned that efficiency, reducing costs, and developing the skills of staff are the main reasons behind applying benchmarking. One of the participants said:

Benchmarking process keeps us on the lookout to learn modern methods and training and capacity building for our staff and therefore the transfer of these programs to our staff.

While a limited number of participants talked about other objectives of the application of benchmarking, including improving financial performance, achieving employee satisfaction, and improving reputation. 
Table 2. The objectives of the application of benchmarking in the hotel sector

\begin{tabular}{lll}
\hline Benefits & Number of participants & Percentage \\
\hline Increasing the level of competitiveness & 10 & 83.33 \\
Improving the quality of outputs & 7 & 58.33 \\
Customers satisfaction & 7 & 58.33 \\
Improving performance & 6 & 50 \\
Increasing profitability & 6 & 50 \\
Achieving the effectiveness & 6 & 50 \\
Achieving the efficiency & 5 & 41.67 \\
Reducing costs & 5 & 41.67 \\
Developing the skills of staff & 5 & 41.67 \\
Benefiting from training programs at an advanced level & 5 & 41.67 \\
Improving financial performance & 2 & 16.67 \\
Achieving employee satisfaction & 2 & 16.67 \\
Improving reputation & 2 & 16.67 \\
\hline
\end{tabular}

The majority of participants of the second question focused on achieving competitiveness as the main objective of applying benchmarking in their business. This result is consistent with the reality since 2007 when Petra was designated one of the New Seven Wonders of the World. This global position of Petra increased the awareness of it as an important tourist destination which increased the number of tourists from around the world. This development increased the competition between service companies in Petra. The results are in line with Ross (1999), Roden \& Dale (2000), Freytag \& Hollensen (2001), Milohnic \& Cerovic (2007), Melia (2011), and Patiar et al. (2012) that assessing competitiveness is one of the major objectives of benchmarking with competitors to follow the recent market trends.

\subsection{Obstacles to the Adoption of Benchmarking}

Regarding the question about the obstacles facing the hotel sector in Petra in the adoption of benchmarking, respondents indicated that there are significant obstacles to be discussed. In addition to the lack of understanding of benchmarking techniques and objectives among few hotels, ten participants stressed the problem of regional conditions and consequences of the Arab Spring which constituted a permanent threat to the stability of the businesses, especially the tourism sector, which is the most affected sector. Respondents indicated that when they adopt a successful model, it remains an external variable which they cannot control, because environmental conditions make comparative conditions incomplete. The impact of events has led to the decline in this sector significantly according to Ali et al. (2012) and Al-Hamarneh (2013).

One participant said:

Despite the existence of the problem of the instability of the surrounding environment, we are always looking for comparable models.

Although environmental change and sensitivity is considered a driver of benchmarking employment (Eraqi, 2006), the instability of political environment in the Middle East causes instability of the volume of business as well as instability in business plans, which makes the employment of new strategy cost more and gives less benefit.

Regarding the internal limitations, six participants spoke about the problem of coordination between the various entities within the company, while four spoke about the problem of the lack of an effective system of information; three spoke about the existence of mistakes in choosing the right model; two talked about the financial problems, the problems of shortage of competence, and technical capacity along with expertise in human resources.

Table 3. Obstacles to the adoption of benchmarking

\begin{tabular}{lll}
\hline Obstacles & Number of participants & Percentage \\
\hline Regional conditions (mainly Arab Spring) & 10 & 83.33 \\
Coordination between the various entities & 6 & 50 \\
Lacking an effective system of information & 4 & 33.33 \\
$\begin{array}{l}\text { Mistakes in choosing the right model } \\
\text { Financial problems }\end{array}$ & 3 & 25 \\
$\begin{array}{l}\text { Shortage of competence and technical capacity and } \\
\text { expertise in human resources }\end{array}$ & 2 & 16.67 \\
\hline
\end{tabular}


Table 3 indicates that highest number of participants answered that the great obstacle to applying benchmarking in Petra is the political regional conditions surrounding Jordan. The rest of obstacles are related to internal managerial problems, and organizational structure such as coordination between the variaus entities and lack of an effective system of information. The remaining obstacles that the interviewees discussed include mistakes in choosing the right model, financial problems, shortage of competence and technical capacity and expertise in human resources which are present in many companies. In supporting this, Kumar \& Chandra (2001) argued that not all organisations find it easy to employ benchmarking tools effectively as a result of lack of a complete understanding of benchmarking.

Furthermore, it is stated in the related literature that internal financial, human resources, information, and knowledge factors are considered among the benchmarking obstacles (such as Omachonu \& Ross, 1994; Bergin et al., 2000).

\section{Conclusion, Implications and Recommendations}

The purpose of this paper was to assess the adoption level of benchmarking in the hotel sector in the city of Petra in Jordan along with its benefits and limitations. Twelve face-to-face interviews were conducted with the owners and business managers of hotels that range from small independent to large international chain hotels.

In relation to the aims of understanding the objectives and limitations of benchmarking application within the hotel sector in Petra, the results indicated that the level of adoption as well as the awareness of the benchmarking was moderate, with more than two-thirds of the interviewees were well to moderately informed about benchmarking concepts and techniques. The results also showed (from the perspective of business owners and managers in Petra) that the most important aims of applying benchmarking are to increase competitiveness in the tourism market, to improve the quality of the outputs, and to achieve customers' satisfaction. The area of competitiveness is of worth here; the literature supports that the competitive environment is one of the major drives of benchmarking as businesses need to follow current trends to be competitive. The results of the interviews support that achieving competitive advantage and success in conducting business requires the adoption of benchmarking as a way of effective performance.

One of the most important results is the negative impact of the regional political conditions and the consequences of the Arab Spring revolutions on the tourism and hotel sector. It is the main obstacle which prevents the adoption of benchmarking in the hotel sector in Petra. This result, which builds on previous studies, contributes to clarifying the impact of political conditions on tourism sector quality issues.

In conclusion, the implications of the current study would affect those who believe less in the value of benchmarking in following the trends of competition. Benchmarking is a useful application when it comes to quality measurement and understanding the behavior of the market and the competitors. Moreover, enhancing the application of benchmarking to take the advances of its important aims and objectives in the hotel sector is of great importance.

The study had a number of limitations including the value of mixing methods with rich statistical analysis to take a broader view of the benchmarking adoption and benefits. In addition, the comparisons with the situation before the Arab Spring and after, the comparison with Jordan and the neighboring countries was not possible due to the instability of the tourism and hotel sector because of the political situation within these countries.

Finally, this study recommended that the impact of political conditions on quality issues from the perspective of tourism should be carefully studied in details due to external variables. Further research based on comparisons between the adoption of benchmarking, objectives and limitations was recommended to analyze the situation before and after the Arab Spring, as well as to compare Jordan with the regional countries in the Middle East and the effect of the Arab Spring on benchmarking adoption, objectives and limitations. Furthermore, further research on benchmarking in other tourism sector components in Petra other than hotels is recommended in order to gain an overall picture of the benchmarking of the destination competitiveness as a general aim, such components may include travel agencies, tour guides, and local related businesses.

\section{References}

AbuKhalifeh, A. N., \& Som, A. P. M. (2013). The antecedents affecting employee engagement and organizational performance. Asian Social Sciences, 9(7), 41-46. http://dx.doi.org/10.5539/ass.v9n7p41.

Ahire, S., Golhar, D., \& Waller, M. (1996). Development and validation of TQM implementation constructs. Decision Scission, 27(1), 23-56. http://dx.doi.org/10.1111/j.1540-5915.1996.tb00842.x 
Al-ababneh, M. (2014). Classifying Jordanian hotels based on their TQM implementation. DIRASAT: Administrative Sciences, 41(2), 482-496.

Al-Fawaeer, M., Hamdan, K. B., \& Al-Zu'bi, H. L. (2012). A Study of Benchmarking Influence on Customer Satisfaction. International Journal of Business and Management, 7(8), 108-114.

Al-Hamarneh, A. (2013). International Tourism and Political Crisis in the Arab World - from 9/11 to the "Arab Spring". e-Review of Tourism Research, 10(5/6), 100-109.

Ali, A., Arifin, Z., \& Hasim, S. (2012). The Challenges of Tourism in the Countries of the Arab Spring Revolutions. Advances in Natural and Applied Sciences, 6(7), 1162-1171.

AL-Omaim, N. (2002). An empirical investigation of total quality management in the Kingdom of Saudi Arabia: a proposed generic framework of best practice. Unpublished Ph.D. Dissertation, Bradford University, UK.

Al-Tarawneh, H. (2014). The Utilization of Benchmarking in the Jordanian Banking Sector. Journal of Management Research, 6(3), 49-57.

Asrofah, T., Zailani, S., \& Fernando, Y. (2010). Best practices for the effectiveness of benchmarking in the Indonesian manufacturing companies. Benchmarking: An International Journal, 17(1), 115-143. http://dx.doi.org/10.1108/14635771011022343

Attiany, M. S. (2014). Competitive Advantage Through Benchmarking: Field Study of Industrial Companies Listed in Amman Stock Exchange. Journal of Business Studies Quarterly, 5(4), 41-51.

Bergin, S., Jago, L. K., \& Deery, M. (2000). Benchmarking in the hospitality industry: an important but misinterpreted concept. Australian Journal of Hospitality Management, 7(2).

Biazzo, S., \& Bernardi, G. (2003). Organisational Self-assessment options A classification and a conceptual map for SMEs. International Journal of Quality \& Reliability Management, 20(8), 881-900. http://dx.doi.org/10.1108/02656710310493616

Cano, M., Drummond, S., Miller, C., \& Barclay, S. (2001). Learning from others: Benchmarking in diverse $\begin{array}{llll}\text { tourism enterprises. Total Quality } & \text { Management, } & \text { 12(7\&8), } & \text { 974-980. }\end{array}$ http://dx.doi.org/10.1080/09544120100000023

Drever, E. (1995). Using Semi-Structure Interviews in Small-Scale Research. Glasgow: The Scottish Council for Research in Education.

Elmuti, D., \& Kathawala, Y. (1997). An Overview of Benchmarking Process: A Tool for Continuous Improvement and Competitive Advantage. Benchmarking for Quality Management and Technology, 4(4), 229-243. http://dx.doi.org/10.1108/14635779710195087

Eraqi, M. I. (2006). Tourism Services Quality (TourServQual) in Egypt, the viewpoints of external and internal customers. Benchmarking: An International Journal, 13(4), 469-492. http://dx.doi.org/10.1108/14635770610676308

Evans, J. R. (2005). Total Quality Management, Organisation, and Strategy (4th ed.). South-Western: Thomson Corporation.

Ford, M., Evans, J. R., \& Matthews, C. H. (2004). Linking self-assessment to the external environment: An exploratory study. International Journal of Operations \& Production Management, 24(11), 1175-1187. http://dx.doi.org/10.1108/01443570410563287

Freytag, P., \& Hollensen, S. (2001). The process of benchmarking, benchlearning and benchaction. The TQM Magazine, 13(1), 25-34. http://dx.doi.org /10.1108/09544780110360624

Goldstein, K. A., \& Primlani, R. V. (2012). Current trends and opportunities in hotels sustainability. HVS Global Hospitality Services. Retrieved from http://www.hvs.com/Content/3218.pdf

Hayek, B., Haddad, J., Mosa, M., Al-Atiyat, N., Buser, C., Mutz, D., \& Zein, K. (2008, July). Environmental and Economic Improvement through Implementation of Cleaner Production in Hospitality Sector in Jordan: Case Studies in Four Hotels. Paper presented at the International Conference on Environmental Performance of Tourist Accommodation Sector in Euro-Med Countries, Petra, Jordan.

Hazbun, W. (2006). Explaining the Arab Middle East tourism paradox. The Arab World Geographer, 9(3), 206-218. 
Inglis, A. (2005). Quality Improvement, Quality Assurance, and Benchmarking: Comparing two frameworks for managing quality processes in open and distance learning. The International Review of Research in Open and Distributed Learning, 6(1).

Jaafreh, Z. B., \& Al-abedallat, A. Z. (2013). The Effect of Quality Management Practices on Organizational Performance in Jordan: An Empirical Study. International Journal of Financial Research, 4(1), 93-109. http://dx.doi.org/10.5430/ijfr.v4n1p93

Kapiki, S. T., Mou, L., \& Fu, J. (2014). Assessment of the Lodging Industry Profitability Performance: Invest in Independent or Chain Ownership?. TURIZAM, 18(2), 84-94. http://dx.doi.org/10.2139/ssrn.2459498

Kosar, L. (2011, September). Benchmarking method for quality evaluation in hotel industry. Paper presented at The Contemporary Trends in Hospitality and Tourism Conference, Novi Sad, Serbia.

Kozak, M. (2002). Destination benchmarking. Annals of Tourism Research, 29(2), 497-519. http://dx.doi.org/10.1016/S0160-7383(01)00072-X

Kumar, S., \& Chandra, C. (2001). Enhancing the effectiveness of benchmarking in manufacturing organizations. Industrial Management \& Data Systems, 101(2), 80-89. http://dx.doi.org/10.1108/02635570110384357

Melia, D. (2011). Critical Success Factors and Performance Management and Measurement: Hospitality Context. Dublin Institute of Technology.

Milohnic, I., \& Cerovic, Z. (2007). Benchmarking and Quality of Small Hotels in Croatia: An Explorative Study. Management, 2(1), 25-35.

Ministry of Tourism and Antiquities Jordan. (2014). Tourism Statistical Newsletter. Retrieved from http://mota.gov.jo/Contents/Tourism_Statistical_Newsletter_2014Ar.aspx

Motwani, J. (2001). Critical factors and performance measures of TQM. The TQM Magazine, 13(4), 292-300. http://dx.doi.org/10.1108/13683040010362300

Mustafa, M. (2010). Tourism and Globalization in the Arab World. International Journal of Business and Social Science, 1(1), 37-48.

Narayan, B., Rajendran, C., \& Sai, L. P. (2008). Scales to measure and benchmark service quality in tourism industry: a second-order factor approach. Benchmarking: An International Journal, 15(4), 469-493. http://dx.doi.org/10.1108/14635770810887258

Oakland, J. (2003). Total Quality Management: Text with Cases (3rd ed.). Oxford: Butterworth Heinemann.

Omachonu, V. K., \& Ross, J. R. (1994). Principles of Total Quality. Delray Beach, FL: St. Lucie Press.

Patiar, A., Davidson, M. C. G., \& Wang, Y. (2012). Competition, total quality management practices, and performance: evidence from upscale hotels. Tourism Analysis, 17, 195-211. http://dx.doi.org/10.3727/108354212X13388995267904

Ravikanth, P., \& Reddy, P. P. (2014). Benchmarking of Andhrapradesh and Mardin. International Journal of Current Engineering and Technology, 4(1), 411-416.

Riessman, C. K. (2004). Narrative Analysis. In M. S. Lewis-Beck, A. Bryman, \& T. F. Liao (Eds.), Encyclopedia of Social Science Research Methods (pp. 705-709). Newbury Park, CA: Sage.

Roden, S., \& Dale, B. G. (2000). Understanding the language of quality costing. The TQM Magazine, 12(3), 179-185. http://dx.doi.org/10.1108/09544780010326362

Ross, J. E. (1999). Total Quality Management, Text, Cases and Readings (3rd ed.). St. Lucie Press.

Sajjad, F., \& Amjad, D. S. (2012). Role of Benchmarking in Total Quality Management: case of Telecom Service Sector of Pakistan. Business Management Dynamics, 1(8), 34-44.

Saunders, M., Lewis, P., \& Thornhill, A. (2003). Research Methods for Business Students (3rd ed.). London: Financial Times Prentice Hall.

Suttapong, K., \& Tian, Z. (2012). Performance Benchmarking for Building Best Practice in Small and Medium Enterprises (SMEs). International Journal of Business and Commerce, 1(10), 46-60.

Taji, E. T. (2004). Marketing Strategies for Tourism Recovery in Jordan (Emphasis on Niche Market). The Netherlands: Maastricht School of Management. 
Tavana, M., Mohebbi, B., \& Kennedy, D. T. (2003). Total quality index: a benchmarking tool for total quality management. Benchmarking: An International Journal, 10(6), 507-527. http://dx.doi.org/10.1108/14635770310505157

Zairi, M., \& Paul, L. (1994). Practical Benchmarking: The Complete Guide. London: Chapman and Hall.

Zigan, K., \& Zeglat, D. (2010). Intangible resources in performance measurement systems of the hotel Industry. Facilities, 28(13/14), 597-610. http://dx.doi.org/10.1108/02632771011083667

\section{Copyrights}

Copyright for this article is retained by the author(s), with first publication rights granted to the journal.

This is an open-access article distributed under the terms and conditions of the Creative Commons Attribution license (http://creativecommons.org/licenses/by/3.0/). 